\title{
The epidemiology of medical emergency contacts outside hospitals in Norway - a prospective population based study
}

\author{
Erik Zakariassen ${ }^{1,2^{*}}$, Robert Anders Burman ${ }^{1}$, Steinar Hunskaar ${ }^{1,3}$
}

\begin{abstract}
Introduction: There is a lack of epidemiological knowledge on medical emergencies outside hospitals in Norway. The aim of the present study was to obtain representative data on the epidemiology of medical emergencies classified as "red responses" in Norway.

Method: Three emergency medical dispatch centres (EMCCS) were chosen as catchment areas, covering 816000 inhabitants. During a three month period in 2007 the EMCCs gathered information on every situation that was triaged as a red response, according to The Norwegian Index of Medical Emergencies (Index). Records from ground ambulances, air ambulances, and the primary care doctors were subsequently collected. International Classification of Primary Care - 2 symptom codes (ICPC-2) and The National Committee on Aeronautics (NACA) Score System were given retrospectively.

Results: Total incidence of red response situations was 5105 during the three month period. 394 patients were involved in 138 accidents, and 181 situations were without patients, resulting in a total of 5180 patients. The patients' age ranged from 0 to 107 years, with a median age of 57, and 55\% were male. 90\% of the red responses were medical problems with a large variation of symptoms, the remainder being accidents. $70 \%$ of the patients were in a non-life-threatening situation. Within the accident group, males accounted for $61 \%$, and $35 \%$ were aged between 10 and 29 years, with a median age of 37 years. Few of the 39 chapters in the Index were used, A10 "Chest pain" was the most common one (22\% of all situations). ICPC-2 symptom codes showed that cardiovascular, syncope/coma, respiratory and neurological problems were most common. 50\% of all patients in a sever situation (NACA score 4-7) were $>70$ years of age.

Conclusions: The results show that emergency medicine based on 816000 Norwegians mainly consists of medical problems, where the majority of the patients have a non-life-threatening situation. More focus on the emergency system outside hospitals, including triage and dispatch, and how to best deal with "everyday" emergency problems is needed to secure knowledge based decisions for the future organization of the emergency system.
\end{abstract}

\section{Introduction}

Persons in need of acute medical assistance are supposed to come in contact with the emergency care system by calling a three digits emergency number (113) to an emergency medical dispatch centre (EMCC). The 19 EMCCs are responsible for alarming the out-of-hospitals emergency resources like ambulances services (ground and air) and primary care doctors on-call.

\footnotetext{
* Correspondence: erik.zakariassen@isf.uib.no

${ }^{1}$ National Centre for Emergency Primary Health Care, Uni Health, Bergen, Norway, Kalfarveien 31, 5018 Bergen, Norway
}

\section{Norway, Kaffarveien 31,5018 Bergen, Norway}

For all calls to an EMCC, trained nurses use The Norwegian Index of Medical Emergencies (Index) [1] to classify the medical problem into one of three different levels of response; green, yellow and red, the latter indicating immediate need of help (potentially or a manifest life-threatening situation). When an emergency situation is classified as red, there will be transmitted a simultaneous radio alarm from the EMCC to doctors on-call and the ambulances in the relevant area.

Even though emergency medicine is considered an important part of the health care system, little is known about the incidence and management of medical

(c) 2010 Zakariassen et al; licensee BioMed Central Ltd. This is an Open Access article distributed under the terms of the Creative Commons Attribution License (http://creativecommons.org/licenses/by/2.0), which permits unrestricted use, distribution, and 
emergencies outside hospitals in Norway. Emergency medicine is not a formal speciality for doctors in Norway. Still, treatment of critically ill or injured people is defined as emergency medicine. Earlier white papers and plans concerning the organisation of the emergency services underscore the lack of national statistics and scarce epidemiological knowledge [2-4]. It has for long been anticipated a rate of about 10 red responses per 1000 inhabitants per year, but this figure has not been supported by valid statistics or scientific studies [3]. Data from a representative sample of Norwegian out-of-hours districts showed a rate of 9 red responses per 1000 inhabitants per year, but this number was based on data from local emergency communication centres, not EMCCs $[5,6]$. A recent study from a single island municipality with approximately 4000 inhabitants found an incidence of 27 medical emergencies per 1000 inhabitants per year [7]. However, the definition of an emergency was wider in this study than the classification of a red response based on the Index of Medical emergencies from EMCCs.

There seems to be a scarce literature with broad epidemiological approach to pre-hospital emergencies in general. Most studies deal with specific emergency problems like cardiac arrest, chest pain or trauma [8-14]. One study in Norway has a wider epidemiological scope [7]. More epidemiological knowledge is needed to make the right decisions for policy makers and leaders of the health care services.

To obtain representative data on the epidemiology of medical emergencies classified as "red response" by the EMCCs, we performed a large prospective population based study.

\section{Materials and methods}

For data collection we chose and cooperated with a strategic sample of three EMCCs, located at Haugesund, Stavanger and Innlandet hospitals, covering Rogaland, southern part of Hordaland, Hedmark, and Oppland counties, covering a total of $69581 \mathrm{~km}^{2}$ (21\% of the total area ofNorway) and 816000 inhabitants (18\% of the total population). Data registration was performed prospectively during a period of three months, from October $1^{\text {st }}$ to December $31^{\text {st }} 2007$.

\section{Variables}

All EMCCs use a software system called Acute Medical Information System (AMIS) to record all incoming situations. Usage of the AMIS system results in an electronic form with registration of each incident (not the individual patient). The AMIS form contains basic information about the situation, the patient(s), all available logistics (date, time registration for incoming alarm and all alarms and electronic messages sent to the different prehospital resources, who responded and when), and to where the patients are transported (left at scene, home, casualty clinic, hospital).

Based on the immediate available information, the EMCC operator (usually a specially trained nurse) gives the situation a clinical criteria code with a response level based on the Index [1]. The Index is based on ideas from the Criteria Based Dispatch system in the US [15], and was first published in 1994. Clinical symptoms, findings and situations are categorised into 39 chapters. Each chapter is subdivided into a red, yellow and green criteria based section, correlating to the appropriate level of response. Red colour is defined as an "acute" response, with the highest priority. Yellow colour is defined as an "urgent" response, with a high, but lower priority. Green colour is defined as a "non-urgent" response, with the lowest priority.

Copies of all AMIS forms involving situations classified as red responses were sent the project manager every second week throughout the study. The EMCCs also sent copies of ambulance records from all red responses which involved ground or boat ambulances. In situations where doctors on-call or air ambulances had been involved, copies of medical records were requested by mail from the project manager directly to the person or agency involved. Several reminders were needed during collection of medical records from different parts of the health care system and continued until October 2008. To secure a uniform recording of the variables in the AMIS program, a meeting between the persons in charge of the participating EMCCs was held.

Based on information from all AMIS forms and medical records we classified the situations according to the International Classification of Primary Care - 2 (ICPC 2) [16]. The ICPC-2 is structured into 7 components and 17 chapters from $\mathrm{A}$ to $\mathrm{Z}$ depending on the body system to which the problem belongs (table 1 ).

Component 1 (codes -01 to -29) provides codes for symptoms and complaints. The analyses in this study were based on codes from the symptom component solely. Each patient was given one code only (e.g. D01 for abdominal pain or N07 for convulsions). For further analyses the symptom-codes were aggregated into clinically connected and appropriate groups based on the chapters from A to Z. ICPC codes were classified in medical records from the doctors on-call. All other ICPC codes were classified by two members of the research team with experience in emergency medicine. Main symptom was used for ICPC coding

Based on all available information according to The National Committee on Aeronautics (NACA) Score System [17], the severity of the medical problem was classified (table 2).

The NACA score system was chosen because it is easy to use retrospectively and the air ambulances use 
Table 1 International Classification of Primary Care (ICPC)

\begin{tabular}{ll}
\hline ICPC & Body system \\
\hline A & General and unspecified \\
B & Blood, blood-forming organs, lymphatic, spleen \\
D & Digestive \\
F & Eye \\
$H$ & Ear \\
K & Circulatory \\
L & Musculoskeletal \\
N & Neurological \\
P & Psychological \\
$R$ & Respiratory \\
$S$ & Skin \\
$T$ & Endocrine, metabolic and nutritional \\
$U$ & Urology \\
$W$ & Pregnancy, childbearing, family planning \\
$X$ & Female genital system \\
Y & Male genital system \\
$Z$ & Social problems \\
\hline
\end{tabular}

Table 2 National Committee on Aeronautics (NACA)

\begin{tabular}{|c|c|}
\hline $\begin{array}{l}\text { Score } \\
\text { level }\end{array}$ & Patient status \\
\hline NACA 0 & No injury or illness \\
\hline NACA 1 & Not acute life-threatening disease or injury \\
\hline NACA 2 & $\begin{array}{l}\text { Acute intervention not necessary; further diagnostic } \\
\text { studies needed }\end{array}$ \\
\hline NACA 3 & $\begin{array}{l}\text { Severe but not life threatening disease or injury; acute } \\
\text { intervention necessary }\end{array}$ \\
\hline NACA 4 & Development of vital (life threatening) danger possible \\
\hline NACA 5 & Acute vital (life threatening) danger \\
\hline NACA 6 & Acute cardiac or respiratory arrest \\
\hline NACA 7 & Death \\
\hline
\end{tabular}

NACA score as a routine for their patients. The patient's status is classified from 0 to 7 , zero indicating no disease or injury, while seven indicates the patient being dead. NACA score was in the analyses categorised as NACA 0-1, indicating a patient either with no symptoms/injuries or in no need of medical treatment, NACA 2-3, indicating need of medical help where value 3 indicates need of hospitalisation, but still not a life-threatening situation. NACA 4-6 indicates potentially (4) and definitely life-threatening medical situations (5 and 6) and NACA 7 is a dead person. NACA scores were classified prospectively in patients transported by air ambulance, and the scores were found in the medical records. All other NACA scores were classified by two members of the research team with experience in emergency medicine. In case of multi-patient accidents the most severely injured patient was included from each situation.

\section{Statistical analyses}

The statistical analyses were performed using Statistical Package for the Social Sciences (SPSS version 15). Standard univariate statistics were used to characterise the sample. Skewed distributed data are presented as median with $25-75 \%$ percentiles. Rate is presented as numbers of red responses per 1000 inhabitants per year with a $95 \%$ confidence interval $(\mathrm{CI})$. A p-value of $<0.05$ was considered significant. Index categories were merged into the five most used (A01/A02 "Unconscious", A05 "Ordered mission", A06 "Inconclusive problem", A10 "Chest pain" and A34/A35 "Accidents") and one category containing the rest, called "All Other" in the analyses. In the analysis of diurnal variations, NACA scores were dichotomised to non life-threatening or lifethreatening situations. In 64 patients we were not able to extract information on gender, patients' whereabouts in 82 situations and where patients where brought to in 50 situations. In 435 situations it was not possible to decide NACA score and in 39 situations ICPC symptoms score.

\section{Ethics and approvals}

Approval of the study was given by the Privacy Ombudsman for Research, Regional Committee for Medical Research Ethics, and the Norwegian Directorate of Health.

\section{Results}

The three participating EMCC-districts collected 5738 AMIS forms for the study, of which 633 were excluded, due to e.g. situations not being red responses and duplicates (fig 1).

Total incidence of red response situations was then 5 105 during the three month period corresponding to a rate of 25.1 (24.4-25.7) situations per 1000 inhabitants per year. Innlandet had a rate of 30.6 (29.4-31.8), Stavanger 20.0 (19.0-21.0) and Haugesund 22.9 (21.4-24.3) Differences in rates between the three EMCC areas was all statistically significant $(\mathrm{p}<0.000)$. In 104 situations the mission was aborted (no patients), six situations concerned allocation of ambulance resources (no patients) and 71 situations were support to other emergency units (fire and police departments, no patients). 394 patients were involved in 138 accidents, resulting in 256 more patients than situations in which 77 situations had 2 patients, 30 situations had 3 patients, and 16, 9 and 6 situations had 4, 5 and 6 or more patients, respectively. The total number of patients was 5180 which corresponds to a rate of $25.5(24.7-26.1)$ patients per 1 000 inhabitants per year. Of the 256 extra patients from the accidents, $98 \%$ had a NACA score of 3 or lower, one was dead. The 256 extra patients, all interrupted missions, allocations of ambulances, and support to 


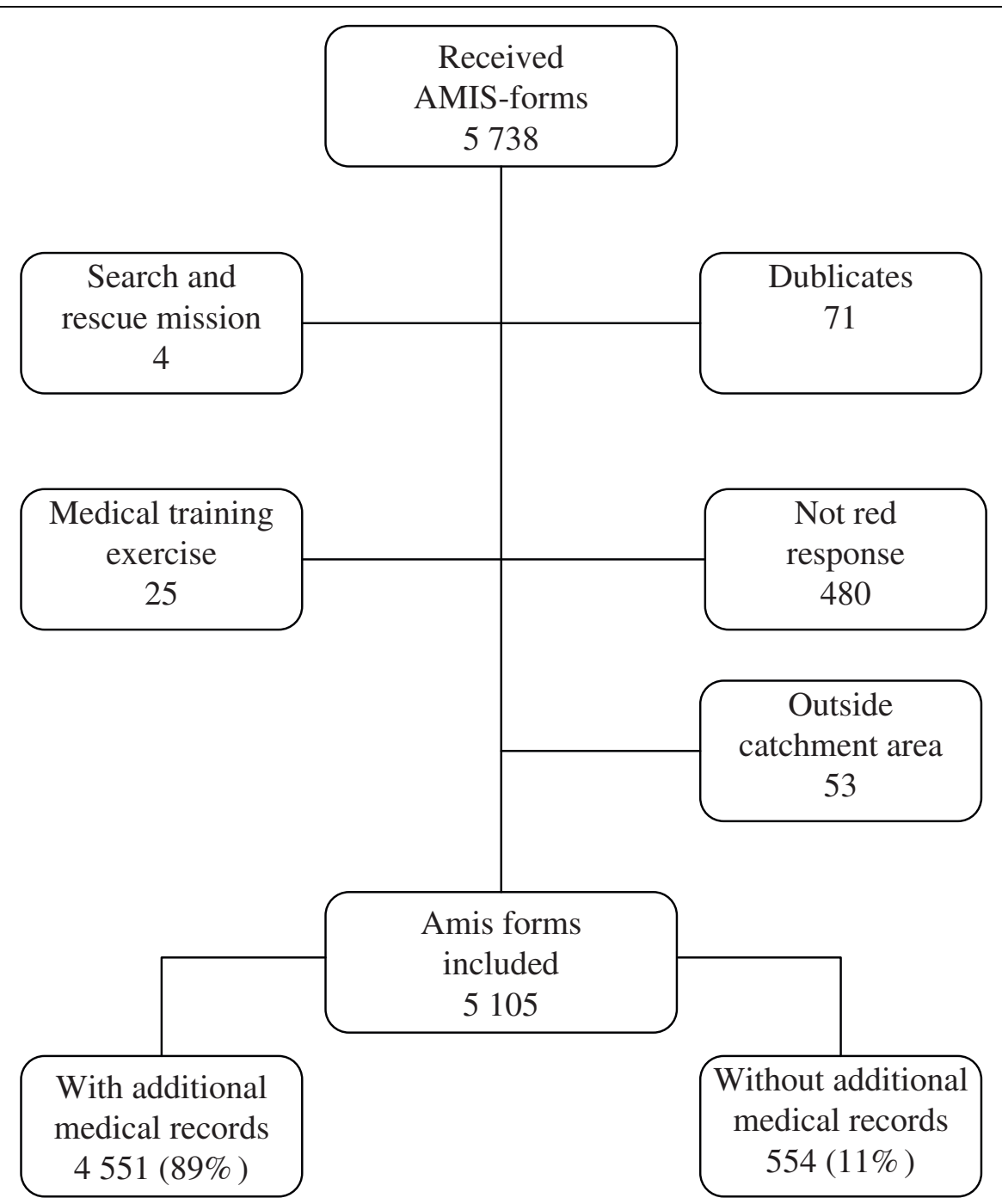

Figure 1 Is a flow chart of total collected, excluded and included AMIS forms.

other emergency units were excluded from further statistical analyses, and the material thus consists of the remaining 4924 red response situations with the same number of patients.

\section{Demography and Index categories}

The patients' age ranged from 0 to 107 years, with a median age of 57 (33-75). The gender distribution showed $55 \%$ men with median age 55 , and $45 \%$ women with median age 58 . Table 3 shows the five most common Index categories. The mostly used Index category was A10 "Chest pain" for both genders, and more than $80 \%$ of the patients with chest pain were over the age of 50. Index category A34/A35 "Accidents" constituted $12 \%$, where $35 \%$ of the patients were between 10 and 29 years, and males accounted for $61 \%$.
The incidence of red responses was higher during daytime (0800-1529) compared to night time (2300-0759) for most of the Index categories, except for category "all other" which had only minor skewness around the clock (table 4). A34/A35 "Accidents" showed the highest incidence during daytime with a proportion of $45 \%$ (table 4 ).

A29 "Breathing difficulties" was the most used Indexcategory in the "all other" group with nearly $5 \%$ of the total. Approximately half of all patients in the youngest age group had "all other" medical problems and convulsions (A23) was the most common Index category with $14 \%$ of the situations. Seven Index categories were each used five times or less and six were not used at all.

\section{Severity of injury and illness}

NACA-score could be set in 4.48 (91\%) of the 4924 situations with patients (table 4 ). Males constituted 
Table 3 The most frequent used Index categories by patients' gender, age, whereabouts and to where the patients were brought.

\begin{tabular}{|c|c|c|c|c|c|c|c|c|c|c|c|c|c|c|}
\hline & \multicolumn{2}{|c|}{$\begin{array}{c}\mathrm{A} 01 / 02 \\
\text { Unconscious }\end{array}$} & \multicolumn{2}{|c|}{$\begin{array}{c}\text { A05 } \\
\text { Ordered mission* }\end{array}$} & \multicolumn{2}{|c|}{$\begin{array}{c}\text { A06 } \\
\text { Inconclusive } \\
\text { problem }\end{array}$} & \multicolumn{2}{|c|}{$\begin{array}{c}\text { A10 } \\
\text { Chest pain }\end{array}$} & \multicolumn{2}{|c|}{$\begin{array}{c}\text { A34/35 } \\
\text { Accidents }\end{array}$} & \multicolumn{2}{|c|}{$\begin{array}{l}\text { All other } \\
\text { categories }\end{array}$} & \multicolumn{2}{|c|}{ Total } \\
\hline & $\mathrm{n}$ & $\%$ & $\mathrm{n}$ & $\%$ & $n$ & $\%$ & $\mathbf{n}$ & $\%$ & $\mathrm{n}$ & $\%$ & $n$ & $\%$ & $\mathrm{n}$ & $\%$ \\
\hline Patients & 410 & 8 & 864 & 18 & 707 & 14 & 1098 & 22 & 565 & 12 & 1280 & 26 & 4924 & 100 \\
\hline \multicolumn{15}{|l|}{ Male } \\
\hline 0-9 years & 11 & 6 & 44 & 24 & 24 & 14 & 2 & 1 & 15 & 8 & 85 & 47 & 181 & 100 \\
\hline $10-29$ years & 34 & 8 & 55 & 14 & 58 & 14 & 13 & 3 & 119 & 30 & 123 & 31 & 402 & 100 \\
\hline 30-49 years & 38 & 7 & 80 & 15 & 70 & 13 & 111 & 21 & 97 & 19 & 128 & 25 & 524 & 100 \\
\hline 50-69 years & 62 & 7 & 133 & 16 & 132 & 16 & 275 & 33 & 70 & 9 & 158 & 19 & 830 & 100 \\
\hline$>70$ years & 81 & 11 & 126 & 18 & 131 & 18 & 211 & 29 & 32 & 5 & 139 & 19 & 720 & 100 \\
\hline Total & 226 & 9 & 438 & 16 & 415 & 16 & 612 & 23 & 333 & 12 & 633 & 24 & 2657 & 100 \\
\hline \multicolumn{15}{|l|}{ Female } \\
\hline $0-9$ years & 20 & 16 & 20 & 16 & 11 & 10 & 1 & 1 & 8 & 6 & 63 & 51 & 123 & 100 \\
\hline $10-29$ years & 28 & 8 & 56 & 16 & 39 & 11 & 12 & 3 & 76 & 21 & 151 & 42 & 362 & 100 \\
\hline 30-49 years & 29 & 7 & 80 & 19 & 55 & 13 & 67 & 16 & 50 & 12 & 152 & 35 & 433 & 100 \\
\hline 50-69 years & 23 & 5 & 81 & 17 & 75 & 15 & 156 & 32 & 45 & 9 & 110 & 23 & 490 & 100 \\
\hline$>70$ years & 77 & 10 & 171 & 21 & 110 & 14 & 249 & 31 & 31 & 4 & 157 & 20 & 795 & 100 \\
\hline Total & 177 & 8 & 408 & 19 & 290 & 13 & 485 & 22 & 210 & 9 & 633 & 29 & 2203 & 100 \\
\hline \multicolumn{15}{|l|}{ Patients' whereabouts } \\
\hline At home & 243 & 9 & 349 & 12 & 416 & 15 & 833 & 30 & 87 & 3 & 882 & 31 & 2810 & 100 \\
\hline Casualty clinic & 4 & 3 & 115 & 77 & 3 & 2 & 17 & 11 & 1 & 1 & 10 & 6 & 150 & 100 \\
\hline Doctor's surgery & 2 & 1 & 105 & 54 & 4 & 2 & 62 & 32 & 4 & 2 & 19 & 9 & 199 & 100 \\
\hline Public area & 113 & 9 & 65 & 6 & 221 & 19 & 94 & 8 & 442 & 37 & 249 & 21 & 1184 & 100 \\
\hline Hospitals & 0 & 0 & 137 & 87 & 0 & 0 & 9 & 6 & 0 & 0 & 11 & 7 & 157 & 100 \\
\hline Nursing home & 22 & 9 & 64 & 27 & 34 & 15 & 51 & 22 & 2 & 1 & 60 & 26 & 233 & 100 \\
\hline Other & 13 & 12 & 12 & 11 & 21 & 19 & 20 & 18 & 15 & 14 & 29 & 26 & 110 & 100 \\
\hline Total & 397 & 8 & 849 & 18 & 699 & 15 & 1086 & 22 & 551 & 11 & 1260 & 26 & 4842 & 100 \\
\hline \multicolumn{15}{|l|}{ Patients brought to } \\
\hline Casualty clinic & 57 & 8 & 76 & 10 & 151 & 21 & 155 & 21 & 105 & 14 & 187 & 26 & 731 & 100 \\
\hline Hospital via casualty clinic & 27 & 5 & 76 & 15 & 100 & 19 & 127 & 24 & 52 & 10 & 138 & 27 & 520 & 100 \\
\hline Directly hospital, doctor involved & 107 & 6 & 544 & 32 & 145 & 8 & 424 & 25 & 159 & 9 & 337 & 20 & 1716 & 100 \\
\hline Directly hospital, doctor not involved & 102 & 9 & 87 & 7 & 175 & 15 & 274 & 23 & 175 & 15 & 364 & 31 & 1177 & 100 \\
\hline Remained on site & 42 & 8 & 55 & 11 & 82 & 16 & 100 & 19 & 43 & 8 & 200 & 38 & 522 & 100 \\
\hline Deceased & 64 & 38 & 12 & 7 & 37 & 22 & 10 & 6 & 14 & 9 & 30 & 18 & 167 & 100 \\
\hline Taken care of by other & 5 & 12 & 3 & 7 & 11 & 27 & 2 & 5 & 8 & 20 & 12 & 29 & 41 & 100 \\
\hline Total & 404 & 8 & 853 & 18 & 701 & 15 & 1092 & 22 & 556 & 11 & 1268 & 26 & 4874 & 100 \\
\hline
\end{tabular}

The variables have some missing data and the total may not add up to 4924 for all groups.

* Mission ordered by health personnel or other emergency units, i.e. transport directly to hospital or ambulance assistance to other emergency

$68 \%$ of the 246 patients with NACA $6-7$. Patients $>70$ years accounted for $50 \%$ of the 1280 patients with potentially/manifest life-threatening medical situations pronounced dead (NACA 4 and higher). Median age of the dead patients was 69 (53-81).

More than $60 \%$ of the patients were in category NACA $2-3$. Also a large majority of the accidents (81\%) were given NACA-score $0-3$, indicating non-life threatening situations. Considering the 166 patients that were pronounced dead on arrival or resuscitated without return of spontaneous circulation (NACA 7), 64 (39\%) were given the code A01/A02 "Unconscious", 37 (22\%) A06 "Inconclusive problem", 14 (8\%) A34/A35 "Accidents", and 10 (6\%) A10 "Chest pain". The percentage of patients with non life-threatening conditions increased from $70 \%$ at daytime to $74 \%$ at night, while life-threatening conditions 
Table 4 The most frequent used Index categories by time of day and NACA-score.

\begin{tabular}{|c|c|c|c|c|c|c|c|c|c|c|c|c|c|c|}
\hline & \multicolumn{2}{|c|}{$\begin{array}{c}\mathrm{A} 01 / 02 \\
\text { Unconscious }\end{array}$} & \multicolumn{2}{|c|}{$\begin{array}{c}\text { A05 } \\
\text { Ordered mission }\end{array}$} & \multicolumn{2}{|c|}{$\begin{array}{c}\text { A06 } \\
\text { Inconclusive problem }\end{array}$} & \multicolumn{2}{|c|}{$\begin{array}{c}\text { A10 } \\
\text { Chest pain }\end{array}$} & \multicolumn{2}{|c|}{$\begin{array}{l}\text { A34/35 } \\
\text { Accidents }\end{array}$} & \multicolumn{2}{|c|}{$\begin{array}{l}\text { All other } \\
\text { categories }\end{array}$} & \multicolumn{2}{|c|}{ Total } \\
\hline & $\mathbf{n}$ & $\%$ & $\mathrm{n}$ & $\%$ & $\mathrm{n}$ & $\%$ & $n$ & $\%$ & $\mathrm{n}$ & $\%$ & $\mathrm{n}$ & $\%$ & $\mathrm{n}$ & $\%$ \\
\hline \multicolumn{15}{|l|}{ Time of day } \\
\hline 0800-1529 & 170 & 41 & 367 & 43 & 275 & 39 & 393 & 36 & 256 & 45 & 439 & 34 & 1897 & 39 \\
\hline $1530-2259$ & 137 & 34 & 292 & 34 & 266 & 38 & 368 & 34 & 211 & 38 & 447 & 35 & 1721 & 35 \\
\hline 2300-0759 & 103 & 25 & 199 & 23 & 160 & 23 & 332 & 30 & 97 & 17 & 388 & 31 & 1279 & 26 \\
\hline Total & 410 & 100 & 858 & 100 & 701 & 100 & 1093 & 100 & 561 & 100 & 1274 & 100 & 4897 & 100 \\
\hline \multicolumn{15}{|l|}{ NACA-score } \\
\hline $0-1$ & 38 & 10 & 44 & 6 & 95 & 15 & 87 & 9 & 101 & 19 & 86 & 7 & 451 & 10 \\
\hline $2-3$ & 163 & 43 & 465 & 59 & 418 & 65 & 631 & 65 & 326 & 62 & 747 & 63 & 2750 & 61 \\
\hline $4-6$ & 117 & 30 & 265 & 34 & 96 & 15 & 243 & 25 & 83 & 16 & 318 & 27 & 1122 & 25 \\
\hline 7 & 64 & 17 & 11 & 1 & 37 & 5 & 10 & 1 & 14 & 3 & 30 & 3 & 166 & 4 \\
\hline Total & 382 & 100 & 785 & 100 & 646 & 100 & 971 & 100 & 524 & 100 & 1118 & 100 & 4489 & 100 \\
\hline
\end{tabular}

Due to some missing data total numbers will not add up to 4924 for all groups.

decreased from $30 \%$ at daytime to $26 \%$ at night. Differences in NACA distribution between the districts were not statistical significant $(\mathrm{p}>0.05)$.

\section{Patients' whereabouts and final level of care}

Table 3 also describes the patients' whereabouts and where the patients were brought, by Index categories. Overall, $58 \%$ of the 4924 patients were residing at home or at private facilities, while one fourth were in public areas. The primary health care services (casualty clinics, doctors' surgeries and nursing homes) constituted $12 \%$ of the patients' whereabouts. $77 \%$ of the situations with A10 "Chest pain" were in private homes and $80 \%$ of the situations with A34/A35 "Accidents" were in public places.

A total of 3413 (70\%) patients were brought to a hospital, either via the casualty clinic $(11 \%)$ or directly with (35\%) or without $(24 \%)$ being examined by a doctor first. Patients who remained on site accounted for $11 \%$ of the patients. The table also shows that in $26 \%$ of the situations, the casualty clinics were directly involved in patient care, either as final place of treatment or by examination and subsequent referrals to hospital. Considering the accidents alone, $28 \%$ of the 556 patients were brought to a casualty clinic. Among the 77 patients with diabetes as the main cause of contact with the EMCC, $73 \%$ remained on site after treatment.

\section{ICPC symptom score}

In 4551 (92\%) patients we retrieved one or more medical record, and in $99 \%$ of all patients a symptom-code was registered. Table 5 shows the symptom distribution where $89 \%$ had medical symptoms, while injuries/traumas accounted for $11 \%$ of the patients. Cardiovascular symptoms was the most common symptom group $(\mathrm{N}=1$ $389,28 \%$ ), and loss of consciousness second, accounting for 945 of the situations (19\%). Chest pain or pain related to the heart dominated the cardiovascular patients with 95\%. Of the 465 patients categorised under "Other", 23\% had a problem related to pregnancy or labour.

Most of the symptom groups were more or less equally gender distributed for all ages, except for traumas/injuries with a large male majority (63\% of the 521 situations). Cardiovascular symptoms were common among the men over the age of 30 , with a peak incidence in the age group "50-69 years" $(\mathrm{N}=346 ; 42 \%)$, while the female patients with cardiovascular symptoms tended to be older with a peak incidence in the age group "> 70 years" $(\mathrm{N}=329 ; 42 \%)$. Traumas were most common in the age group 10-29 years, dominated by young males with $29 \%$ of the 399 situations in this group. In the youngest age group (0-9 years), neurological symptoms dominated in both genders, with $32 \%$ of the 180 situations among the boys, and 43\% of the 123 situations among the girls.

Table S1; additional file 1 shows the Index categories A05 "Ordered mission" and A06 "Inconclusive problem" by gender, age and the patients' whereabouts. More than a third of the patients with code A05 had cardiovascular symptoms, while the symptom "Injury/trauma" (6\%) was used the least. For gender there were only minor differences between the symptom groups.

\section{Discussion}

Based on our comprehensive, prospective and population based study, estimated rate of red response patients was about 25 per 1000 inhabitants per year in Norway. However, differences in rates between the three districts 
Table 5 Patient distribution according to the ICPC-2 classification system with frequencies, rate and national estimate per year

\begin{tabular}{|c|c|c|c|c|c|}
\hline ICPC symptoms & ICPC-code (n) & $\mathbf{N}$ & $\%$ & $\begin{array}{r}\text { Rate per } \\
1000 / \text { year }\end{array}$ & $\begin{array}{r}\text { National } \\
\text { estimate/year }\end{array}$ \\
\hline Cardiovascular & & 1389 & 28 & 6.8 & 31100 \\
\hline Chest/heart pain & A11 (808) K01 (513) & & & & \\
\hline Other cardiovascular symptoms & K29 (68) & & & & \\
\hline Loss of consciousness & & 945 & 19 & 4.6 & 21200 \\
\hline Syncope/coma & A06/07 (945) & & & & \\
\hline Respiratory & & 472 & 10 & 2.3 & 10600 \\
\hline Dyspnoea/breathing problems & R02/04 (430) & & & & \\
\hline Other respiratory symptoms & R29 (42) & & & & \\
\hline Neurological & & 592 & 11 & 2.9 & 13300 \\
\hline Convulsion & N07 (324) & & & & \\
\hline Other neurological symptoms & N29 (268) & & & & \\
\hline Digestive & & 195 & 4 & 1.0 & 4400 \\
\hline Abdominal pain/cramps & D01 (113) & & & & \\
\hline Other digestive symptoms & D29 (82) & & & & \\
\hline Psychiatric & & 296 & 6 & 1.5 & 6600 \\
\hline Acute alcohol abuse & P16 (113) & & & & \\
\hline Other psychiatric symptoms & P29 (182) & & & & \\
\hline Injury/trauma & & 531 & 11 & 2.6 & 11900 \\
\hline Laceration/cut, skin & S18 (101) & & & & \\
\hline Other skin symptoms other & S29 (34) & & & & \\
\hline Other musculoskeletal symptoms & L29 (396) & & & & \\
\hline Other & & 465 & 10 & 2.3 & 10400 \\
\hline Endocrine/metabolic symptoms & T29 (11) & & & & \\
\hline Urinary/male genital symptoms & U29 (7) Y29 (5) & & & & \\
\hline Pregnancy/female genital symptoms & W29 (106) X29 (1) & & & & \\
\hline Assault/harmful event/problem & Z25 (12) & & & & \\
\hline General symptoms & A29 (317) & & & & \\
\hline Eye symptoms & F29 (6) & & & & \\
\hline Not classified & & 39 & 1 & 0.2 & \\
\hline Subtotal & & 4924 & 100 & 24.2 & 110000 \\
\hline Excluded patients & & 256 & & 1.3 & \\
\hline Total & & 5180 & & 25.5 & 116000 \\
\hline
\end{tabular}


were pronounced. Index category A10 "Chest pain" was the most used category (22\%), while A34/A35 "Accidents" accounted for $12 \%$ of the total. More than $70 \%$ of all red responses were found to be non life-threatening situations with NACA score $=3$. Nearly $60 \%$ of the patients were at home or other private facilities. $70 \%$ of the patients were brought to hospitals, $24 \%$ of them without being examined by a doctor beforehand. One fourth of the patients were brought to a casualty clinic.

The strengths of our study include its completeness, representativity, and number of variables included. In the course of a three month period we were able to prospectively collect a complete material of more than 5 000 red responses based on a population close to 820 000 inhabitants, about $20 \%$ of the Norwegian population. In nearly $90 \%$ of all situations we retrieved records from ground and air ambulances, casualty clinics, general practitioners and doctors on-call. Together with the complete set of AMIS forms, this yields a comprehensive material for analysis of the objectives of the study. There are some limitations of the study. Severity score (NACA) on patients was assessed retrospectively based on medical records and may therefore have lower accuracy (except for situations where the air ambulances had been involved and their medical records were retrieved). The presented results are based on the EMCCs' definition of an emergency based on the Index. Undertriaged patients are thus not included.

Rate of red responses in Innlandet was higher then the rates in Stavanger and Haugesund. We see no obvious explanation for this. If the percentage of NACA 4 and above was higher in Stavanger and Haugesund compared to Innlandet, it could indicate higher accuracy and a lower level of "overtriage". This was not the fact and differences in NACA distribution between the districts were not significant. The study was not designed to investigate possible differences in triage pattern between the EMCCs.

A comparable study from Norway based on 4400 inhabitants demonstrate mainly the same distribution between the different ICPC scores. For instance, cardiovascular problems were most common with $32 \%$, respiratory diseases $11 \%$ and psychiatric problems constituted 5\% of the situations [7]. Accidents accounted for $16 \%$ of the situations [7] which is higher percentage than in our study where accidents accounted for $11 \%$.

Patients in the age group 50 and older represented nearly $60 \%$ of all red response situations, and persons older than 70 constituted $31 \%$. This places emphasis on some of the upcoming challenges in emergency care, both in the primary and the secondary health care system, namely an increasingly older population and therefore more pressure on the emergency systems both inside and outside hospitals. A recently published white paper emphasised this as an important challenge for the capacity and organization of the health care system in Norway [18]. In the US, the rate of ambulance use among older patients (65 years or older) was found to be four times higher than among younger patients, all levels of responses included [19].

Medical symptoms constituted $90 \%$ of all red response situations and A10 "Chest pain" was the most used Index category for a red response. Of all 39 chapters in the Index only five were used more than $8 \%$, in which two of those represent situations where the problem was already known (A05 "Ordered mission") or the problem could not be disclosed (A06 "Inconclusive problem"). Seven of the chapters were hardly ever used and six were not used at all. A12 "Drowning" was probably not used due to season variation. To the best of our knowledge a throughout evaluation of the Index has never been performed in Norway. The necessity of 39 chapters and the content of the chapters should be evaluated. The large majority of the red responses were given a NACA score indicating non life-threatening situations. Overtriage in dispatch centres is well known and demanding on the resources involved [20-22].

ICPC-2 coding of the symptoms resulted in a large variation of symptoms where $90 \%$ were medical problems, with cardiovascular problems as the most common one. In the category A05 "Ordered mission" cardiovascular symptoms were most common, and in A06 "Inconclusive problem" loss of consciousness was the most common symptom. The latter was probably mainly due to patients with syncope where the obvious reason for loss of consciousness was regarded as unknown.

The results show that patients involved in emergency medical situations have of a large variety of medical problems, where the majority of the patients have a non life-threatening situation. The large variation of medical symptoms stands in contrast to a narrow use of the Index as a decision tool in the EMCCs. More focus towards the emergency system outside hospitals, including triage and dispatch, and how to best deal with "everyday" emergency problems is needed in Norway. The large variety of symptoms and conditions may for instance indicate a need for more diagnostic competence at the scene of the patients. Doctors on-call in the emergency primary care services has to be more involved in emergency situations. More clinical assessment up front may lead to better medical care and to more relevant transportation routes. This challenge is addressed in a plan of action for the future emergency primary health care service in Norway [23]. 
Additional file 1: Table S1: Shows the Index categories A05 Ordered mission and A06 Inconclusive problem distributed by ICPC-2 symptom categories.

Click here for file

[ http://www.biomedcentral.com/content/supplementary/1757-7241-18-9S1.DOC]

\section{Acknowledgements}

This study could not have been carried out without help from the three EMCCs and support from Lars Solhaug, Dag Frode Kjernlie, Sissel Grønlien, and Jan Nystuen from the area of Innlandet, Unni Eskeland and Olav Østebø from the area of Stavanger, and Leif Landa, Kari Hauge Nilsen, and Trond Kibsgaard in the area of Haugesund. We want to thank Pål Renland for valuable help in data coding, Tone Morken for help in statistical challenges, Thomas Knarvik and Lars Myrmel for good discussions about dispatch centres, and all the doctors on-call and personnel at casualty clinics and air ambulance crews who sent us copies of medical records.

\section{Author details}

'National Centre for Emergency Primary Health Care, Uni Health, Bergen, Norway, Kalfarveien 31, 5018 Bergen, Norway. ${ }^{2}$ Department of Research, Norwegian Air Ambulance Foundation, Post Box 94, 1441, Drøbak, Norway. ${ }^{3}$ Section for General Practice, Department of Public Health and Primary Health Care, University of Bergen, Post Box 7804, 5020 Bergen, Norway.

\section{Authors' contributions}

EZ and SH planned and established the project, including the procedures for data collection, and designed the paper. EZ and RAB performed the analyses and drafted the first manuscript. All authors took part in rewriting and approved the final manuscript.

\section{Competing interests}

The authors declare that they have no competing interests.

\section{Received: 13 October 2009}

Accepted: 18 February 2010 Published: 18 February 2010

\section{References}

1. Norwegian Medical Association: Norsk indeks for medisinsk nødhjelp. (Norwegian Index of Emergency Medical Assistance) Stavanger: The Laerdal Foundation for Acute Medicine, 2.12005.

2. Regional Health Authorities: Traumesystem i Norge (Trauma care system in Norway) http://www.helse-sorost.no/stream_file.asp?iEntityld=1567.

3. Ministry of Health and Care Services: Stortingsmelding 43 (1999-2000) Om akuttmedisinsk beredskap. (About emergency preperedness) http://www. regjeringen.no/nb/dep/hod/dok/regpubl/stmeld/19992000/stmeld-nr-431999-2000-html?id=193493.

4. Office of the Auditor General of Norway: Riksrevisjonens undersøkelse av akuttmedisinsk beredskap i spesialisthelsetjenesten. (The OAG's investigation of emergency medical preparedness in the specialist health service. English summary) http://www.riksrevisjonen.no/Search/sider/Results. aspx?k=akuttmedisin

5. Hansen EH, Hunskaar S: Development, implementation, and pilot study of a sentinel network ("The Watchtowers") for monitoring emergency primary health care activity in Norway. BMC Health Serv Res 2008, 8:62.

6. Zakariassen $\mathrm{E}$, Hansen $\mathrm{EH}$, Hunskaar S: Incidence of emergency contacts (red responses) to Norwegian emergency primary health care services in 2007 - a prospective observational study. BMC Scand I Trauma ResusC Emerg Med 2009, 8:30.

7. Rørtveit S, Hunskår S: Akuttmedisinske hendingar i ein utkantkommune. (Medical emergencies in a rural community. English summary) Tidsskr Nor Legeforen 2009, 129:738-42.

8. Bamvita JM, Bergeron E, Lavoie A, Ratte S, Clas D: The impact of premorbid conditions on temporal pattern and location of adult blunt trauma hospital deaths. J Trauma 2007, 63:135-41.

9. Engdahl J, Holmberg M, Karlson BW, Luepker R, Herlitz J: The epidemiology of out-of-hospital 'sudden' cardiac arrest. Resuscitation 2002, 52:235-45.
10. Hansen KS, Morild I, Engesaeter LB, Viste A: Epidemiology of severely and fatally injured patients in western part of Norway. Scand J Surg 2004, 93:198-203.

11. Heskestad B, Baardsen R, Helseth E, Romner B, Waterloo K, Ingebrigtsen T: Incidence of hospital referred head injuries in Norway: A population based survey from the Stavanger region. BMC Scand I Trauma ResusC Emerg Med 2009, 17:6.

12. Kristiansen T, Soreide K, Ringdal KG, Rehn M, Kruger AJ, Reite A, et al: Trauma systems and early management of severe injuries in Scandinavia: Review of the current state. Injury 2009.

13. Soreide K, Kruger AJ, Vardal AL, Ellingsen CL, Soreide E, Lossius HM: Epidemiology and contemporary patterns of trauma deaths: changing place, similar pace, older face. World J Surg 2007, 31:2092-103.

14. Kjøs HO, Lande TM, Eriksson U, Nordhaug D, Karevold A, Haaverstad R: Thorax skader ved et regionalt traumesenter. (Thoracic injuries at a regional trauma centre. English summary) Tidsskr Nor Laegeforen 2007, 127:1496-9.

15. Cully LL, Henwood DK, Clark JJ, Eisenberg MS, Horton C: Increasing the efficiency of emergency medical services by using criteria based dispatch. Ann Emerg Med 1994, 24:867-72.

16. World Health Organization: International Classification of Primary Care, (ICPC-2)., 2http://www.who.int/classifications/icd/adaptations/icpc2/en/ index.html.

17. The National Committee on Aeronautics (NACA). http:/www.medal.org/ visitor/www/Active/ch29/ch29.01/ch29.01.13.aspx.

18. Ministry of Health and Care Services: Stortingsmelding 47 (2008-2009) Samhandlingsreformen. (The Coordination Reform) http://www.regjeringen. no/nb/dep/hod/dok/regpubl/stmeld/2008-2009/stmeld-nr-47-2008-2009-. html?id=567201.

19. Shah MN, Bazarian JJ, Lerner EB, Fairbanks RJ, Barker WH, Auinger $P$, et al: The epidemiology of emergency medical services use by older adults: an analysis of the National Hospital Ambulatory Medical Care Survey. Acad Emerg Med 2007, 14:441-7.

20. Sporer KA, Johnson NJ, Yeh CC, Youngblood GM: Can emergency medical dispatch codes predict prehospital interventions for common 9-1-1 call types?. Prehosp Emerg Care 2008, 12:470-8.

21. Sporer KA, Youngblood GM, Rodriguez RM: The ability of emergency medical dispatch codes of medical complaints to predict ALS prehospital interventions. Prehosp Emerg Care 2007, 11:192-8.

22. Neely KW, Eldurkar J, Drake ME: Can current EMS dispatch protocols identify layperson-reported sentinel conditions?. Prehosp Emerg Care 2000, 4:238-44.

23. National Centre for Emergency Primary Health Care: Handlingsplan for legevakt. (The Emergency Primary Health Care Service, a Plan of Action) http://www.unifobhelse.no/publications.aspx?ci=158.

doi:10.1186/1757-7241-18-9

Cite this article as: Zakariassen et al: The epidemiology of medical emergency contacts outside hospitals in Norway - a prospective population based study. Scandinavian Journal of Trauma, Resuscitation and Emergency Medicine 2010 18:9.

\section{Submit your next manuscript to BioMed Central and take full advantage of:}

- Convenient online submission

- Thorough peer review

- No space constraints or color figure charges

- Immediate publication on acceptance

- Inclusion in PubMed, CAS, Scopus and Google Scholar

- Research which is freely available for redistribution

Submit your manuscript at www.biomedcentral.com/submit
C Biomed Central 